\title{
Electroacupuncture at acupoint ST 37(Shangjuxu) improves function of the enteric nervous system in a novel mouse constipation model
}

\author{
Chao Liang ${ }^{1 \dagger}$, Kaiyue Wang ${ }^{2 \dagger}$, Bin $\mathrm{Xu}^{1}$ and Zhi Yu${ }^{1 *}$
}

\begin{abstract}
Background: Electroacupuncture (EA) at acupoint ST 37 (Shangjuxu) has been used to alleviate gastrointestinal symptoms and improve gastrointestinal motility. However, the mechanisms by which EA affects the enteric nervous system (ENS) have scarcely been investigated. In this study, we investigated whether EA could improve ENS function.

Methods: A constipation model was established by gastric instillation of ice-cold saline daily for 14 days. The constipated mice were divided into two groups: the model group, which was not treated, and the EA group, which received EA at ST 37 at a frequency of 2-15 HZ and an amplitude of $1 \mathrm{~mA}$ for $15 \mathrm{~min}$ a day for 3 days. A further six mice were included as a non-constipated control group. After EA treatment, intestinal propulsion and defecation time were measured. Additionally, in jejunum, ileum and proximal colon myenteric plexus, the expressions of PGP9.5 and nNOS were measured by immunohistochemistry.

Results: The EA group demonstrated significant improvements in carbon propulsion rates and defecation time compared to model group $(P<0.05)$. In addition, after EA, the PGP9.5 and nNOS expression in jejunum, ileum and proximal colonic myenteric plexus was back to normal levels.

Conclusion: This study suggests that EA stimulation at ST 37 is capable of ameliorating intestinal motility dysfunction, and can partly restore enteric neuron function. The ENS can participate in changes in intestinal motility by affecting inhibitory neurons.
\end{abstract}

Keywords: Electroacupuncture(EA), Enteric nervous system(ENS), Gastrointestinal (Gl), Neuronal nitric oxide synthase (nNOS)

\section{Background}

Constipation is a symptom of underlying defects in transit of fecal mass through the gut or in defecation, and is a commonly diagnosed functional gastrointestinal (GI) disorder. Constipation is usually associated with a number of diseases, and is characterized by a series of complex GI symptoms in the absence of mechanical obstruction of the GI tract [1,2]. Diet, side effects of medication, and hormonal disorders may induce constipation [3-5]. Therapy for

\footnotetext{
* Correspondence: mickey28282@sina.com

${ }^{\dagger}$ Equal contributors

${ }^{1}$ Nanjing University of Chinese Medicine, Nanjing 210046, Jiangsu Province, China

Full list of author information is available at the end of the article
}

constipation is largely directed towards treating the symptoms, and most of the treatment methods are uniformly effective [6]. However, these treatments do not address the underlying dysfunction in the GI tract that results in constipation.

Acupuncture as one of the most frequently applied methods in Traditional Chinese Medicine, which has a history of more than 3000 years, has gained increased popularity. In recent years, electroacupuncture (EA) at different acupoints has come to be recognized as a potential effective therapy to treat GI disorder. Preclinical researches have shown that ST 37 could increase GI transit, relieve defecation difficulty and improve life quality [7-9], and indicated that it is effective for constipation. Previous 
experiments have shown chronic and recurrent cold water irritation to stomach might cause long-term effects on bowel movements, which resulted in the GI motility, such as inhibited jejunal and colonic motility [10, 11]. In a cold water-induced rat model of constipation, EA stimulation at ST 37 increases faecal water content, defaecation frequency and GI transit $[12,13]$. ST37 has a positive effect on objective markers of constipation. It is believed that acupuncture at different acupoints exerts different effects on internal organs to restore the homeostatic balance [14-16]. Most previous research has focused on the effects on central and peripheral neural pathways in EA's ameliorating effects on intestinal motility [17]. However, the effects and mechanisms of EA on the enteric nervous system (ENS) have not been widely investigated. The purpose of this study was to investigate whether EA affects the ENS, and to explore local neural mechanism of EA in the gut.

\section{Methods}

\section{Animals}

C57BL/6 J mice (SPF-grade, 3-week-old males, 20-25 g) were purchased from the Model Animal Research Center of Nanjing University (Nanjing, China, license number: SCXK 2013-0005). Animals were housed in a room with $12 \mathrm{~h}$ light-dark cycle (turn on at 8:00 a.m.) maintained at $22 \pm 2{ }^{\circ} \mathrm{C}$ with $60 \%$ humidity and ad libitum access to food and water. All experimental manipulations were undertaken in accordance with the Principles of Laboratory Animal Care and the Guide for the Care and Use of Laboratory Animals, published by the National Science Council, China.

\section{Experimental model of constipation}

The mice were randomly divided into two groups: a $0-4{ }^{\circ} \mathrm{C}$ saline-treated group $(n=40)$, and a normal feeding group $(n=10)$, randomly numbered, and raised in single cages that allowed normal access to food and water. Wire netting was used to facilitate the separation and collection of stools. The constipation model was established by gastric instillation of ice-cold $\left(0-4{ }^{\circ} \mathrm{C}\right)$ saline daily for 14 days [18]. To eliminate the influence of biological rhythms, intragastric administrations were conducted at 8:00 am daily for $14 \mathrm{~d}$. Animals were initially administered ice-cold $\left(0-4{ }^{\circ} \mathrm{C}\right)$ saline at a dose of $0.2 \mathrm{~mL} /$ mouse, and then the dose was increased by $0.05 \mathrm{~mL} /$ mouse every $5 \mathrm{~d}$. Control mice were raised normally without intragastric administration of ice-cold saline.

\section{Materials}

Materials used in this study include wire netting (to facilitate the separation and collection of stools); a precision electronic balance (Sartorius Co, Beijing, China); ceramic cups (high temperature-resistant, radius: $2 \mathrm{~cm}$, high: $3.5 \mathrm{~cm}$ ).
Drugs included saline (Sodium chloride injection; Nanjing Chemical Reagent Co, Jiangsu, China), acacia gum (Gum Arabic powder; BASF Chemical Co, Tianjin, China), and black or red carbon powder (Color toner; Sanheng Information Technology Co). Primary antibodies for immunohistochemistry included PGP9.5 (Abcam, Cambridge, $\mathrm{UK}$ ) and nNOS (Abcam, Cambridge, UK). The secondary antibody used was HRP-Polymer Rabbit anti-Mouse IgG (Boster Biotech, Wuhan, China).

Black and red carbon suspensions were prepared as follows: acacia gum $(100 \mathrm{~g})$ was added to $800 \mathrm{~mL}$ of water and boiled until transparent. Then the solution was mixed with black or red carbon powder $(50 \mathrm{~g})$ and boiled three times. After cooling, each solution was diluted with water to $1000 \mathrm{~mL}$ and then stored at $4{ }^{\circ} \mathrm{C}$. The solutions were agitated prior to use.

\section{EA treatment}

After the constipation model was successfully established, the constipated mice were randomly subdivided into two groups ( $n=6$ for each group): the model group, which remained untreated, and the EA group, which received EA at ST 37. EA stimulation was applied by two pairs of stainless steel needles $(0.25 \mathrm{~mm}$ in diameter $)$ inserted bilaterally at ST $37(2 \mathrm{~mm}$ lateral to the anterior tubercle of the tibia and $6 \mathrm{~mm}$ below the knee joint) [19]. After insertion into the acupoint of constipated mice, the needles were stimulated by an EA apparatus (\#HANS-100A, Nan Jing Ji Sheng Medical Treatment Science and Technology Co., China). Electrical stimulus intensity was set at $1 \mathrm{~mA}$ with a frequency of $2-15 \mathrm{~Hz}$. The stimulation was delivered for $15 \mathrm{~min}$ a day for 3 days.

\section{Measurement of intestinal function}

After $12 \mathrm{~h}$ of fasting, mice were intragastrically administrated a suspension of black carbon $(0.3 \mathrm{~mL})$ and killed $10 \mathrm{~min}$ later via cervical dislocation. The section of intestine extending from the pylorus to the ileocecal valve was removed. The full length of the intestinal tract as well as the propulsive distance of black carbon in the tract was measured under a tension-free state, and the ratio of the propulsive distance to the length of the intestinal tract was determined for all groups. Additionally, after $12 \mathrm{~h}$ of fasting, another group of mice were given a red carbon suspension $(0.3 \mathrm{~mL})$, and the time required to defecate the first stool pellet containing the red indicator was recorded.

\section{Tissue preparation and immunohistochemistry}

At the end of the experiment, small intestine (jejunum and ileum) and proximal colon tissue specimens were removed after $12 \mathrm{~h}$ of fasting. Segments approximately $1 \mathrm{~cm}$ in length were opened along the mesenteric border, and immediately fixed by immersion in $4 \%$ paraformaldehyde for $24 \mathrm{~h}$. Then the samples were processed for 
paraffin embedding in vacuum and cut at a thickness of $10 \mu \mathrm{m}$ for immunohistochemistry.

Sections were deparaffinized in xylene and hydrated in a graded solution of ethanol. Activity of endogenous peroxidases was blocked with $3 \%$ hydrogen peroxide. Sections were sequentially incubated in $3 \%$ hydrogen peroxide and blocked with $5 \%$ bovine serum albumin (BSA) for $30 \mathrm{~min}$ at $37{ }^{\circ} \mathrm{C}$. The primary antibodies (Abcam, Cambridge, UK) for PGP9.5 (1:1000) and nNOS (1:800) were applied to the sections and each specimen was incubated in a moist chamber overnight at $4{ }^{\circ} \mathrm{C}$, and then washed for three times in $0.01 \mathrm{~mol} / \mathrm{L}$ phosphatebuffered saline (PBS; pH 7.2). After that, the slides were incubated with horseradish peroxidase (HRP)-Polymer Rabbit anti-Mouse IgG(Boster Biotech, Wuhan, China) for $90 \mathrm{~min}$ at $37^{\circ} \mathrm{C}$, then incubated in 3,3-diaminobenzidine (DAB) solution for 2-5 min. Specificity of the antibody was confirmed by negative control staining in the absence of primary antibody treatment. Two observers evaluated the slides using an Olympus FV500 optical microscope (Olympus, Tokyo, Japan). Positive immunostaining was evaluated at 5 random visual fields at a magnification of 400 . The mean density of positive expression was assessed using image analysis software (Image Pro Plus 6.0).

\section{Statistical analysis}

Data were expressed as mean \pm standard error Statistical analysis was conducted using SPSS 17.0 software with oneway analysis of variance. Data were compared using the

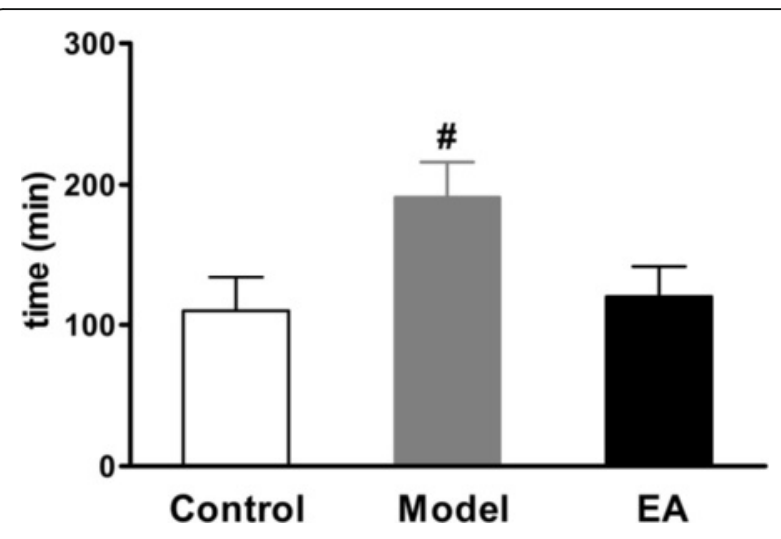

Fig. 2 Measurement of the defecation time. All groups were used in tracking time required for defecation of the first indicator-containing stool pellet. ( $n=6$ for each group), ${ }^{\#} P<0.01$ vs. Control or EA group

Student Newman Keuls post-hoc test. Differences where $P<0.05$ were considered to be statistically significant.

\section{Results}

\section{Effects of EA stimulation on small intestine function}

Carbon intestinal propulsion experiments showed the distances by which black carbon was propelled decreased in constipation models compared to control group (Fig. 1a, $P<0.05$ ). After EA treatment, carbon propulsion rates significantly increased, and did not differ from control group values (Fig. 1b).

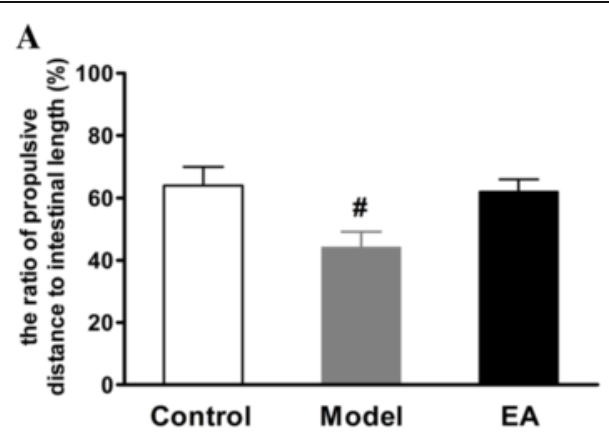

B

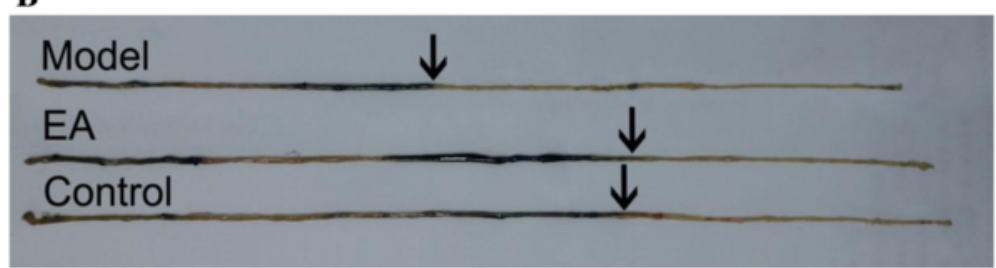

Fig. 1 Measurement of carbon propulsion rate. a: All groups were used in the intestinal propulsion experiment. The distances traveled by black carbon significantly increased in the EA group compared to the Model group. $\mathbf{b}$ : Examples of intestine and black carbon trace for all three groups. ( $n=6$ for each group), ${ }^{\#} P<0.05$ vs. Control or EA group 


\section{Effects of EA stimulation on defecation time}

In this experiment, the defecation time was prolonged in constipation models compared to control group, as would be expected. After EA stimulation treatment, defecation time significantly decreased compared to constipation models and almost returned to normal (Fig. 2).

\section{Effect of EA on total neuronal PGP9.5 protein expression}

Immunohistochemical staining revealed that the number of PGP9.5-positive cells in the constipation model was markedly decreased compared with the control group in the small intestine and proximal colon. After EA treatment, the protein expression of PGP9.5 was significantly increased compared to constipation models in jejunum
(Fig. 3a, b, c), ileum (Fig. 3e, f, g) and proximal colon (Fig. 3i, j, k), but there was no difference compared with the control group, respectively (Fig. 3d, h, l).

\section{Effects of constipation and EA stimulation on nNOS protein expression}

Statistical analysis indicated that the expression of nNOS in constipation models were increased compared with the control group in the in jejunum, ileum and proximal colon. After EA at ST 37, the expression of nNOS was significantly decreased compared to constipation models in jejunum (Fig. 4a, b, c), ileum (Fig. 4e, f, g) and proximal colon (Fig. 4i, j, k), almost returned to normal levels

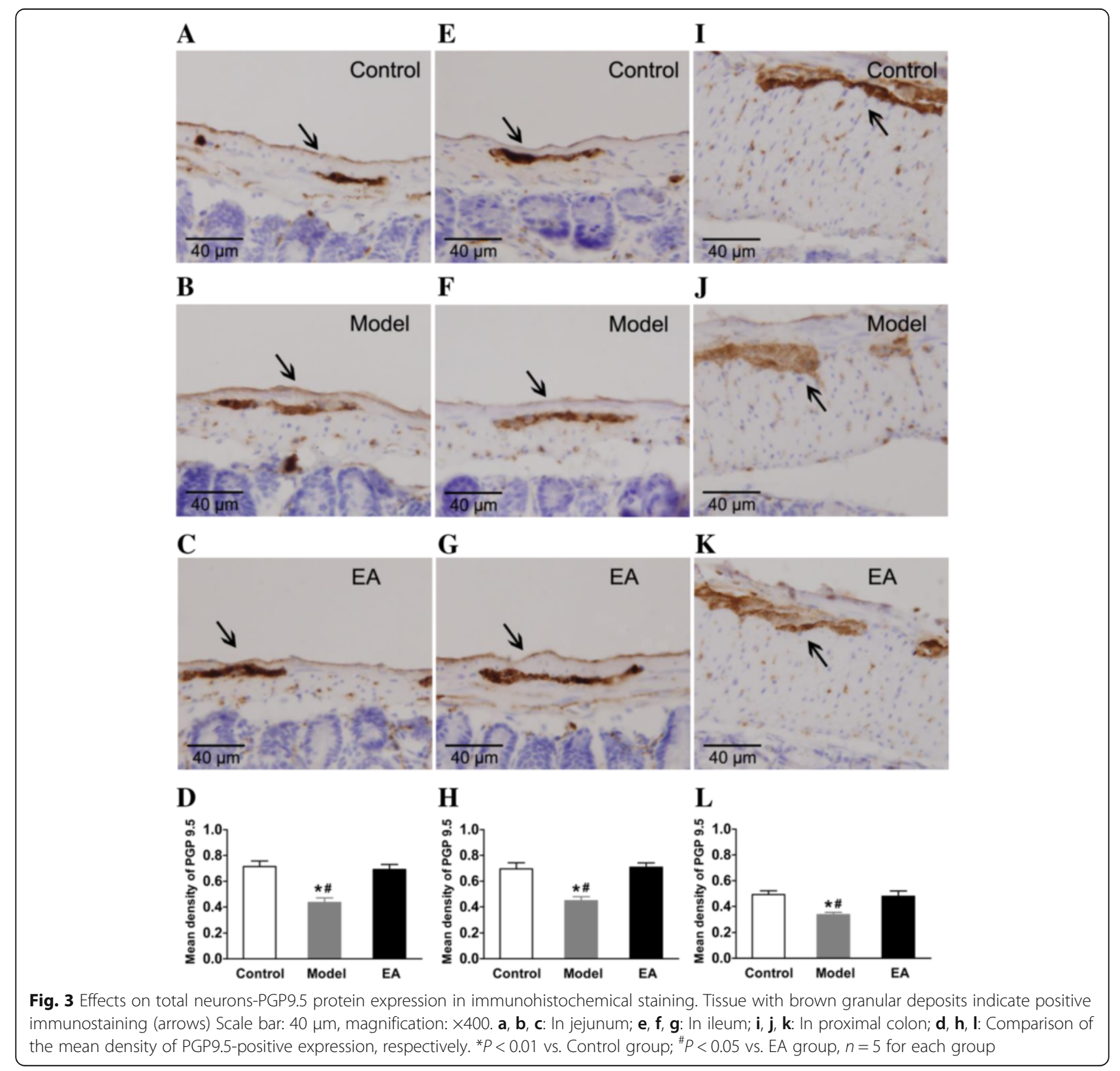




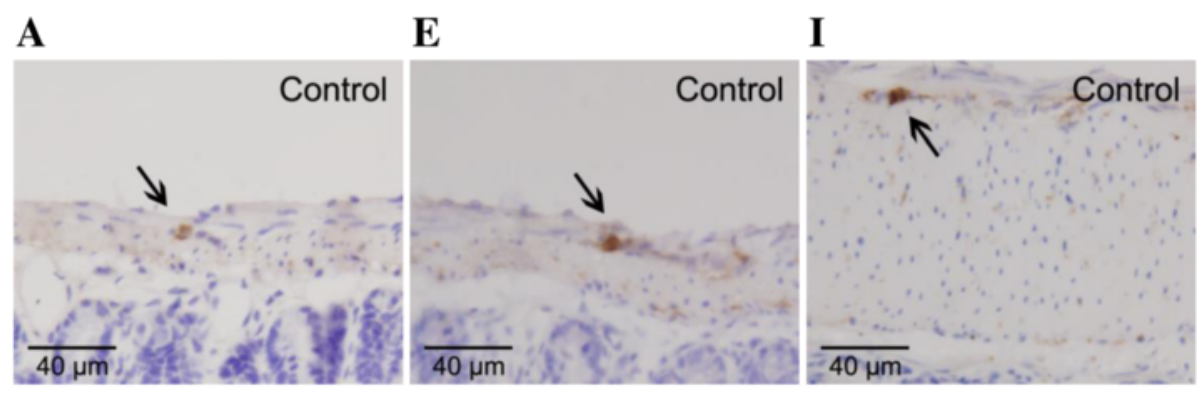

B

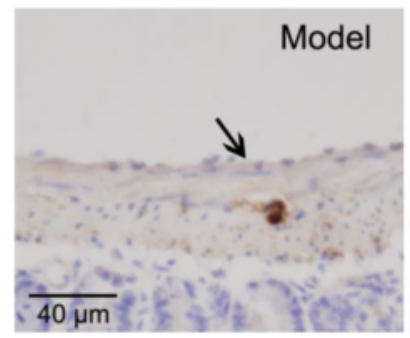

C

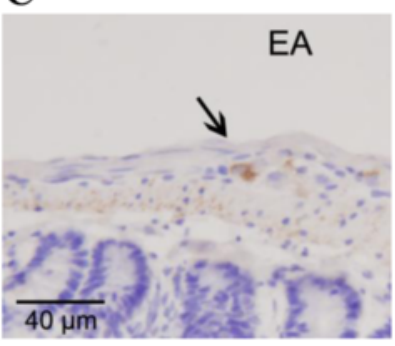

D

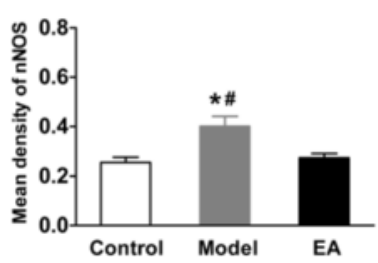

F

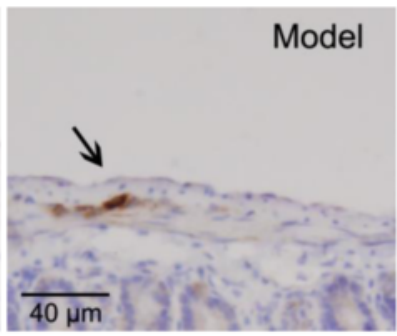

G

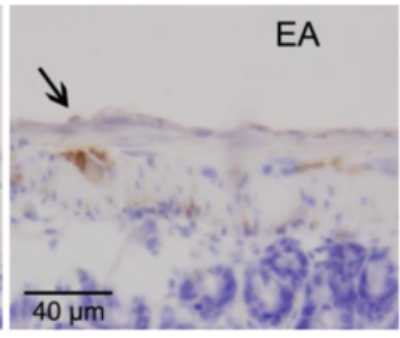

H

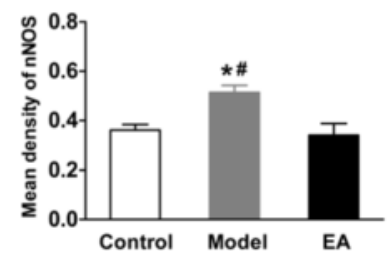

J

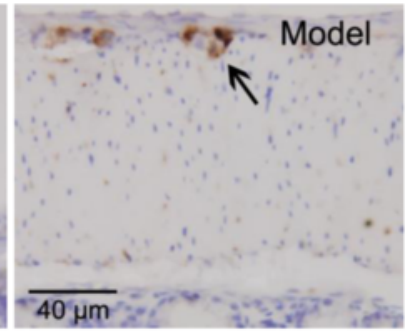

K

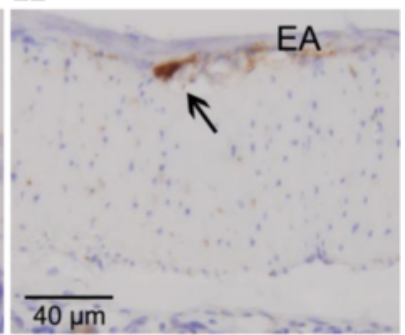

L

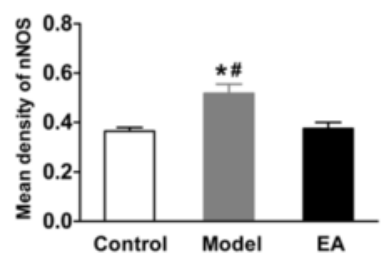

Fig. 4 Effects on nNOS expression in immunohistochemical staining. Tissue with brown granular deposits indicate positive immunostaining (arrows) Scale bar: $40 \mu \mathrm{m}$, magnification: $\times 400)$. a, b, c: In jejunum; $\mathbf{e}, \mathbf{f}, \mathbf{g}$ : In ileum; i, j, $\mathbf{k}$ : In proximal colon; $\mathbf{d}, \mathbf{h}, \mathbf{I}$ : Comparison of the mean density of nNOS-positive expression, respectively. ${ }^{*} P<0.01$ vs. Control group; ${ }^{\#} P<0.05$ vs. EA group, $n=5$ for each group

and there was no difference compared with the control group, respectively (Fig. 4d, h, l).

\section{Discussion}

Acupuncture is beneficial as an alternative treatment for the management of gastrointestinal functional disorders, including constipation, diarrhea and irritable bowel syndrome [20-22]. Although acupuncture has been used as an appropriate adjunct treatment for GI dysfunction disorders, the underlying mechanisms of EA on the ENS have not been well studied.

In this study, the results indicate that EA at ST 37 improved impaired intestine functions, accelerating GI motility. Acupuncture is recognized to have regionally specific effects [23]. ST 37 is located in the hind limb, and some studies have demonstrated that acupuncture at the hind limb increases GI motility [24]. In clinical treatment, ST 37 can improve GI motility and alleviate symptoms, which is effective for treating constipation $[25,26]$. Previous research has focused on the effects of acupuncture on central and peripheral neural pathways; EA stimulation of points on the abdomen can influence sympathetic nerves to the GI tract, while points in the four limbs can influence parasympathetic nerves [27, 28]. Parasympathetic nerves can promote GI peristalsis, while sympathetic nerves inhibit GI movement [29]. Accordingly, the effect of stimulation at ST 37 support these previous results. Stimulation at ST 37 may increase the 
parasympathetic-sympathetic balance and promote GI movement. As the ENS plays an important role in the GI motility, we hypothesized that the ENS could participate in EA stimulation of GI function. The ENS is a complex network of neurons and glia that resides in the myenteric and submucosal plexus of the bowel, and controls many aspects of bowel function [30]. The myenteric plexus, located between longitudinal and circular muscle, primarily controls muscle contraction and relaxation [31]. Therefore, ENS defects may underlie common GI motility problems such as constipation.

Our previous study indicated that irritation with icecold saline caused changes in the ENS in the jejunum, ileum and proximal colonic myenteric plexus [18]. Indeed, immunohistochemistry results showed the protein expression of PGP9.5 after EA stimulation was significantly increased compared to constipation models in the jejunum, ileum and proximal colon myenteric plexus. PGP9.5 is a neuron-specific protein, which can be used to accurately locate enteric neurons and indicate ENS function [32]. In this study, our results indicated that EA may improve enteric neurons and repair the impaired ENS. A previous study found that EA at ST 36 (Zusanli), which is also located in the hind limb, can induce regeneration of lost enteric neurons in a diabetic model [33]. Thus, the enteric neurons in the ENS are likely to be affected by EA stimulation. As we know, abnormal activity of the ENS can have significant effects on the functions of the digestive tract, and many diseases illustrate essential roles of the ENS [34, 35]. In our opinion, EA ameliorates intestinal motility impairment through both central and peripheral neural pathways, which works in concert with the ENS.

Furthermore, the expression of neuronal nitric oxide synthase (nNOS) in the constipation model was significantly increased compared with the control group, and returned to almost normal after EA treatment. In the ENS, nitric oxide $(\mathrm{NO})$ is a major inhibitory neurotransmitter, and is synthesized by neuronal NOS [29]. It has been suggested that, in the ENS, structural abnormalities of the myenteric and submucosal plexus and an abnormal neurotransmitter content have been considered to be responsible for primary chronic constipation [36]. Studies on different parts of the intestine reveal the participation of $\mathrm{NO}$ in the regulation of spontaneous contractions, such as colonic contractile activity [37, 38]. We concluded from our experiments that increased NO in the myenteric plexus might reduce intestinal motility, and be closely related to the development of constipation. In our view, EA at ST 37 can restore the balance of inhibitory neurotransmitters of the enteric neurons, leading to improvement of the impaired ENS function.

\section{Conclusion}

In summary, EA stimulation at ST 37 is capable of ameliorating intestinal motility dysfunction in a mouse constipation model, and can partly restor e enteric neuron function. The ENS can participate in changes in intestinal motility by affecting inhibitory neurons. EA could effects on internal organs, and restore the homeostatic balance via central and peripheral neural pathways working in concert with the ENS.

\section{Abbreviations \\ EA: Electroacupuncture; ENS: Enteric nervous system; Gl: Gastrointestinal; nNOS: Neuronal nitric oxide synthase; NO: Nitric oxide}

\section{Acknowledgments}

We thank Qian Li (Nanjing University of Chinese Medicine) for experimental instruction.

\section{Funding}

This work was supported by the National Key Basic Research Program (973 Program, No. 2011CB505206), the National Natural Science Foundation of China (Nos. 81202744, 81373749, 81574071), and the People Programme (Marie Curie Actions) of the European Union's Seventh Framework

Programme under REA grant agreement No: PIRSES-GA-2013-612589.

Availability of data and materials

Data are all contained within the paper.

\section{Authors' contributions}

Conceived and designed the experiments: CL. Performed the experiments: $\mathrm{CL}$, KW. Wrote the paper: CL. Manuscript editing: ZY BX. All authors read and approved the final manuscript.

\section{Authors' information}

Chao Liang, Ph.D candidate, Major Research Direction: basic research of acupuncture treatment.

\section{Competing interests}

The authors declare that they have no competing interests

Consent for publication

The authors declare that they consent for publication.

\section{Ethics approval}

All procedures had the approval of the Animal Ethics Committee of the Nanjing University of Chinese Medicine.

\section{Author details}

${ }^{1}$ Nanjing University of Chinese Medicine, Nanjing 210046, Jiangsu Province, China. ${ }^{2}$ Xi'an Traditional Chinese Medicine Brain Disease Hospital, Xi'an 710000, China.

Received: 4 May 2016 Accepted: 13 October 2016

Published online: 18 October 2016

\section{References}

1. Park HJ, Jarrett M, Cain K, Heitkemper M. Psychological distress and Gl symptoms are related to severity of bloating in women with irritable bowel syndrome. Res Nurs Health. 2008;31(2):98-107.

2. Choung RS, Locke GR 3rd, Zinsmeister AR, Schleck CD, Talley NJ. Psychosocial distress and somatic symptoms in community subjects with irritable bowel syndrome: a psychological component is the rule. Am J Gastroenterol. 2009;104(7):1772-9.

3. Bittencourt AF, Martins JR, Logullo L, Shiroma G, Horie L, Ortolani MC, et al. Constipation is more frequent than diarrhea in patients fed exclusively by enteral nutrition: results of an observational study. Nutr Clin Pract. 2012:27(4):533-9.

4. Na JR, Oh KN, Park SU, Bae D, Choi EJ, Jung MA, et al. The laxative effects of Maesil (Prunus mume Siebold \& Zucc.) on constipation induced by a lowfibre diet in a rat model. Int J Food Sci Nutr. 2013;64(3):333-45.

5. McCarberg BH. Overview and treatment of opioid-induced constipation. Postgrad Med. 2013;125(4):7-17. 
6. Chiarelli P, Brown W, McElduff P. Constipation in Australian women: prevalence and associated factors. Int Urogynecol J Pelvic Floor Dysfunct. 2000;11(2):71-8.

7. Liu Z, Liu J, Zhao Y, Cai Y, He L, Xu H, et al. The efficacy and safety study of electro-acupuncture for severe chronic functional constipation: study protocol for a multicenter, randomized, controlled trial. Trials. 2013;14:176.

8. Xiong F, Wang Y, Li SQ, Tian M, Zheng CH, Huang GY. Clinical study of electroacupuncture treatment with different intensities for functional constipation patients. J Huazhong Univ Sci Technolog Med Sci. 2014;34(5):775-81.

9. Xu X, Zheng C, Zhang M, Wang W, Huang G. A randomized controlled trial of acupuncture to treat functional constipation: design and protocol. BMC Complement Altern Med. 2014;14:423.

10. Chen DP, Xiong YJ, Tang ZY, Yao QY, Ye DM, Liu SS, et al. Characteristics of deslanoside-induced modulation on jejunal contractility. World J Gastroenterol. 2012:18(41):5889-96.

11. Yang X, Xi TF, Li YX, Wang HH, Qin Y, Zhang JP, et al. Oxytocin decreases colonic motility of cold water stressed rats via oxytocin receptors. World J Gastroenterol. 2014;20(31):10886-94.

12. Zhu X, Liu Z, Qu H, Niu W, Gao L, Wang Y,et al. The effect and mechanism of electroacupuncture at LI11 and ST37 on constipation in a rat model. Acupunct Med. 2016:34(3):194-200.

13. Qin QG, Gao XY, Liu K, Yu XC, Li L, Wang HP, et al. Acupuncture at heterotopic acupoints enhances jejunal motility in constipated and diarrheic rats. World J Gastroenterol. 2014;20(48):18271-8.

14. Inanç BB. A new theory on the evaluation of traditional chinese acupuncture mechanisms from the latest medical scientific point of view. Acupunct Electrother Res. 2015;40(3):189-204.

15. Fabrin S, Soares N, Pezarezi Yoshimura D, Hallak Regalo SC, Donizetti Verri E, de Freitas Vianna JR, et al. Effects of acupuncture at the Yintang and the Chengjiang acupoints on cardiac arrhythmias and neurocardiogenic syncope in emergency first aid. J Acupunct Meridian Stud. 2016;9(1):26-30.

16. Zhao C, Bao C, Li J, Zhu Y, Wang S, Yang L, et al. Moxibustion and acupuncture ameliorate Crohn's disease by regulating the balance between Th17 and Treg cells in the intestinal mucosa. Evid Based Complement Alternat Med. 2015;2015:938054.

17. Iwa M, Matsushima M, Nakade Y, Pappas TN, Fujimiya M, Takahashi T. Electroacupuncture at ST-36 accelerates colonic motility and transit in freely moving conscious rats. Am J Physiol Gastrointest Liver Physiol. 2006;290(2):G285-92.

18. Liang C, Wang KY, Yu Z, Xu B. Development of a novel mouse constipation model. World J Gastroenterol. 2016;22(9):2799-810.

19. Wang SJ, Yang HY, Xu GS. Acupuncture alleviates colorectal hypersensitivity and correlates with the regulatory mechanism of TrpV1 and p-ERK. Evid Based Complement Alternat Med. 2012;2012:483123.

20. Li Y, Zheng H, Zeng F, Zhou SY, Zhong F, Zheng HB, et al. Use acupuncture to treat functional constipation: study protocol for a randomized controlled trial. Trials. 2012;13:104

21. Sun JH, Wu XL, Xia C, Xu LZ, Pei LX, Li H, et al. Clinical evaluation of Soothing Gan and invigorating Pi acupuncture treatment on diarrhea-predominant irritable bowel syndrome. Chin J Integr Med. 2011;17(10):780-5.

22. MacPherson H, Bland M, Bloor K, Cox H, Geddes D, Kang'ombe A, et al. Acupuncture for irritable bowel syndrome: a protocol for a pragmatic randomised controlled trial. BMC Gastroenterol. 2010;10:63.

23. Kaptchuk TJ. Acupuncture: theory, efficacy, and practice. Ann Intern Med. 2002;136(5):374-83.

24. Tada H, Fujita M, Harris M, Tatewaki M, Nakagawa K, Yamamura T, et al. Neural mechanism of acupuncture-induced gastric relaxations in rats. Dig Dis Sci. 2003;48(1):59-68

25. Zhenzhong $L$, Xiaojun $Y$, Weijun $T$, Yuehua $C$, Jie S, Jimeng $Z$, et al. Comparative effect of electroacupuncture and moxibustion on the expression of substance $P$ and vasoactive intestinal peptide in patients with irritable bowel syndrome. J Tradit Chin Med. 2015;35(4):402-10.

26. Chen $\mathrm{CY}$, Ke MD, Kuo CD, Huang $\mathrm{CH}$, Hsueh YH, Chen JR. The influence of electro-acupuncture stimulation to female constipation patients. Am J Chin Med. 2013:41(2):301-13.

27. Noguchi E. Acupuncture regulates gut motility and secretion via nerve reflexes. Auton Neurosci. 2010;156(1-2):15-8.

28. Li YQ, Zhu B, Rong PJ, Ben H, Li YH. Neural mechanism of acupuncturemodulated gastric motility. World J Gastroenterol. 2007;13(5):709-16.

29. Furness JB. The enteric nervous system and neurogastroenterology. Nat Rev Gastroenterol Hepatol. 2012;9(5):286-94.
30. Heanue TA, Pachnis V. Enteric nervous system development and Hirschsprung's disease: advances in genetic and stem cell studies. Nat Rev Neurosci. 2007:8(6):466-79.

31. Furness JB, Callaghan BP, Rivera LR, Cho HJ. The enteric nervous system and gastrointestinal innervation: integrated local and central control. Adv Exp Med Biol. 2014;817:39-71.

32. Sidebotham EL, Woodward MN, Kenny SE, Lloyd DA, Vaillant CR, Edgar DH. Assessment of protein gene product 9.5 as a marker of neural crest-derived precursor cells in the developing enteric nervous system. Pediatr Surg Int. 2001;17(4):304-7.

33. Du F, Wang L, Qian W, Liu S. Loss of enteric neurons accompanied by decreased expression of GDNF and PI3K/Akt pathway in diabetic rats. Neurogastroenterol Motil. 2009;21(11):1229-e114.

34. Matsuda NM, Miller SM, Evora PR. The chronic gastrointestinal manifestations of Chagas disease. Clinics (Sao Paulo). 2009:64(12):1219-24.

35. Di Nardo G, Blandizzi C, Volta U, Colucci R, Stanghellini V, Barbara G, et al. Review article: molecular, pathological and therapeutic features of human enteric neuropathies. Aliment Pharmacol Ther. 2008;28(1):25-42.

36. Wedel T, Roblick U, Gleiss J, Ott V, Eggers R, Kühnel W, et al. Disorders of intestinal innervation as a possible cause for chronic constipation. Zentralbl Chir. 1999;124(9):796-803.

37. Boeckxstaens GE, Hirsch DP, Kodde A, Moojen TM, Blackshaw A, Tytgat GN, et al. Activation of an adrenergic and vagally-mediated NANC pathway in surgery-induced fundic relaxation in the rat. Neurogastroenterol Motil. 1999; 11(6):467-74.

38. Lies B, Beck K, Keppler J, Saur D, Groneberg D, Friebe A. Nitrergic signalling via interstitial cells of Cajal regulates motor activity in murine colon. J Physiol. 2015;593(20):4589-601.

\section{Submit your next manuscript to BioMed Central and we will help you at every step:}

- We accept pre-submission inquiries

- Our selector tool helps you to find the most relevant journal

- We provide round the clock customer support

- Convenient online submission

- Thorough peer review

- Inclusion in PubMed and all major indexing services

- Maximum visibility for your research

Submit your manuscript at www.biomedcentral.com/submit
) Biomed Central 